\title{
Selective Enzyme-Mediated Extraction of Capsaicinoids and Carotenoids from Chili Guajillo Puya (Capsicum annuum L.) Using Ethanol as Solvent
}

\author{
R. I. Santamaría, ${ }^{\dagger}$ M. D. Reyes-Duarte, ${ }^{\dagger}$ E. Bárzana, ${ }^{\ddagger}$ D. Fernando, ${ }^{\S}$ F. M. Gama, ${ }^{\S}$ M. Mota, ${ }^{\S}$ and \\ A. López-Munguía*,‡ \\ Instituto de Biotecnología, UNAM, Apartado Postal 510-3, Cuernavaca, Morelos, 62271, Mexico; \\ Facultad de Química, UNAM, Cd. Universitaria, Mexico 04510 D.F., Mexico; and \\ Centro de Engenharia Biológica, IBQF, Universidade do Minho, Largo do Paço, 4709 Braga Codex, Portugal
}

\begin{abstract}
The selective extraction of capsaicinoids and carotenoi ds from chili guajillo "puya" flour was studied. When ethanol was used as solvent, $80 \%$ of capsaicinoids and $73 \%$ of carotenoids were extracted, representing an interesting alternative for the substitution of hexane in industrial processes. Additionally, when the flour was pretreated with enzymes that break the cell wall and then dried, extraction in ethanol increased to 11 and $7 \%$ for carotenoid and capsaicinoid, respectively. A sel ective two-stage extraction process after the treatment with enzymes is proposed. The first step uses $30 \%$ $(\mathrm{v} / \mathrm{v})$ ethanol and releases up to $60 \%$ of the initial capsaicinoids, and the second extraction step with industrial ethanol permits the recovery of $83 \%$ of carotenoids present in the flour.
\end{abstract}

Keywords: Capsicum annuum; carotenoids; capsai cinoids; selectiveextraction; enzymatic extraction

\section{INTRODUCTION}

There is a worldwide growing interest in natural colorants for the food and pharmaceutical industries. As a result, the consumption of synthetic products has declined due to consumer's concern for food safety and stringent regulations from organizations such as the U.S. Food and Drug Administration and the World Health Organization. Carotenoids are one of the most important groups of natural colorants in the food industry, and the genus Capsicum is a widely used source. Capsaicinoids and carotenoids are found in the oily fraction of several varieties of chili peppers (Capsicum annuum). These colorants are normally commercialized as a dried powder such as paprika or as main components of the oleoresin obtained after extraction with hexane. Color and pungency are dependent on capsicum variety. The Guajillo variety is the most frequently used in the Mexican colorant industries due to its low capsai cin content. On the other hand, capsaicin has interesting properties as a therapeutic agent, particularly as a chemoprotector against mutagenesis or tumorigenesis (Surh et al., 1995), and it is also the active ingredient of pepper spray, a relatively safe weapon (Busker and van Helden, 1998).

It has been reported that after hexane extraction, it is possible to reduce pungency in oleoresin by fractionation with $70 \% \mathrm{v} / \mathrm{v}$ methanol solutions, recovering $87 \%$ of carotenoids and $83 \%$ of capsaicinoids after separation (Balakrishnan and Verghese, 1997). Amaya Guerra et al. (1997) reported the extraction of oleoresin from dried Guajillo pepper with four solvents: ethanol, acetone,

* Author to whom correspondence should be addressed [telephone (52)(73) 116265; fax (52)(73) 172388; e-mail agustin@ibt.unam.mx].

† Instituto de Biotechnol gía.

‡ Facultad de Química.

$\S$ Centro de Engenharia Biológica. ethyl acetate, and hexane. These authors found that the amount of pigment extracted increases with the polarity of the solvent. Hence, ethanol extracted the highest amount of oleoresin, with $82 \%$ of capsaicinoids measured in terms of pungency units and $74 \%$ of carotenoids. They al so reported the fractionation of acetoneextracted oleoresins with a mixture of ethanol/water (9: 1 ) yielding a precipitate with a large proportion of colorants and a solution rich in pungency.

Capsaicinoids are soluble in various solvents such as chlor oform, acetone, ethyl ether, ethyl acetate, methyl chloride, ethanol, and 2-propanol, among others (Suzuki and I wai 1984). Except for the alcohols, these solvents present environmental risks. Nevertheless, due to chemical and toxicological limitations, there is a clear trend in agroindustries to substitute hexane or any other organic solvent for alternative nontoxic solvents, particularly in products for human consumption, with the first option being water or alcohols (Sineiro et al., 1998). In the same context, enzymatic processes have al so been proposed to increase yield and selectivity (Domínguez et al., 1994). Ethanol and 2-propanol have been reported in oil extraction from soybean (Baker and Sullivan, 1983), cottonseed (Abraham et al., 1988, 1991, 1993), and sunflower seeds (Sineiro et al., 1998). Water processes have also been devel oped for the extraction of oil from seeds and vegetables using enzymes to increase the extraction yield (Fullbrook, 1983; Buenrostro and López-Munguía, 1986; Cintra MacGlone et al., 1986; Domínguez et al., 1993, 1994; Shabtai et al., 1998; Rosenthal et al., 1996; Shankar et al., 1997). However, these processes have been applied only to raw materials with oil contents $>20 \%$. In some cases dramatic enhancement of oil extraction is obtained with the use of enzymes (Cintra MacGlone et al., 1986). Microscopy has hel ped to elucidate changes in different plant structures such as oil bodies (Zamski et al., 1987; Napier et al., 


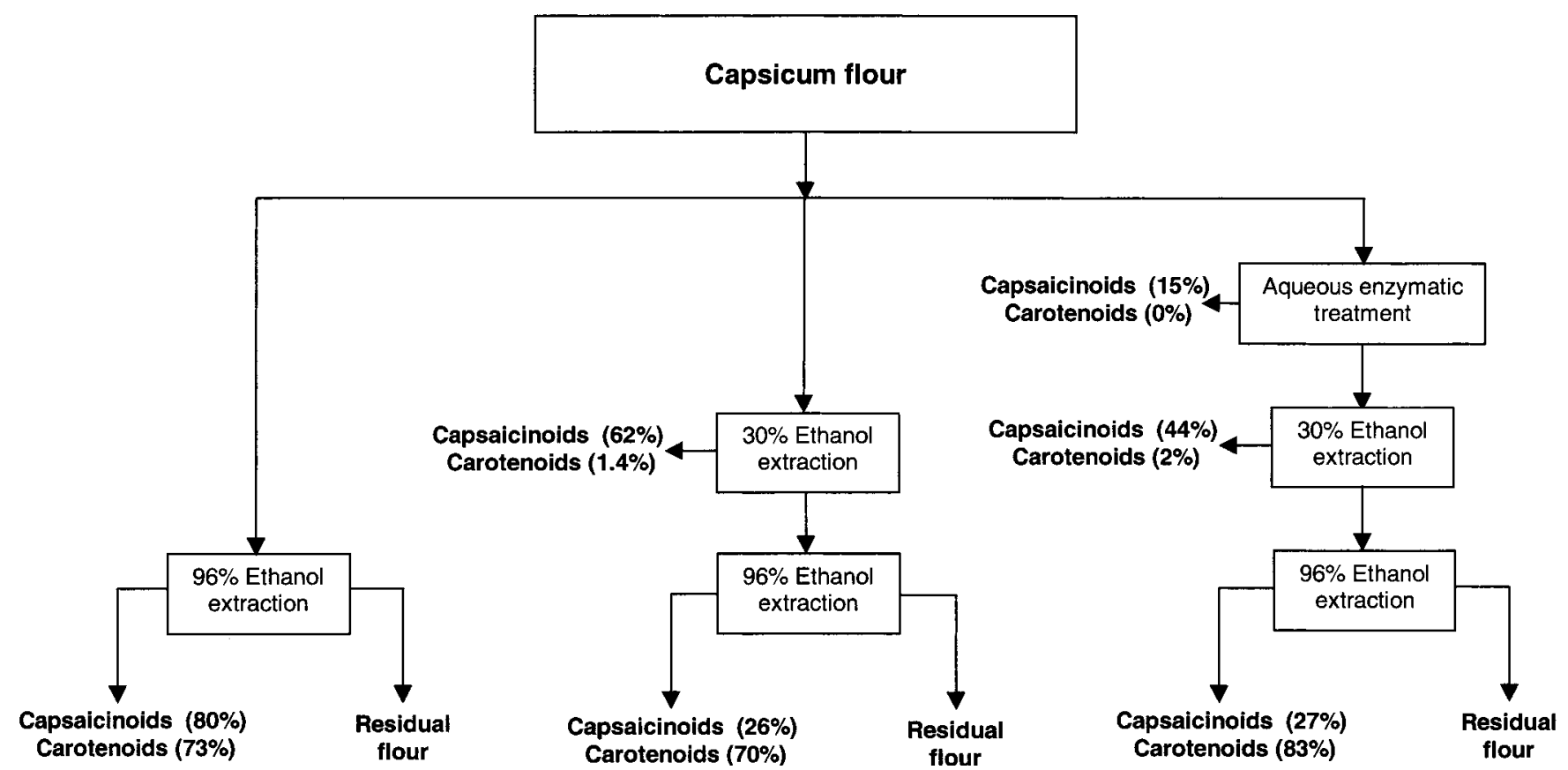

Figure 1. Extraction diagram. Three extraction options were studied: water, industrial ethanol, and ethanol solutions (30\% $\mathrm{v} / \mathrm{v})$. Extraction yields are reported for each step.

1996) and could therefore be applied to analyze the effect of enzymatic action in this kind of process.

In this paper, the extraction conditions of capsaicinoids and carotenoids from Guajillo peppers in ethanol solutions are established. The effect of an enzymatic pretreatment on extraction yield as well as on cell structure by analysis with light microscopy is also established and, finally, a selective extraction for both products in a two-step process is proposed.

\section{MATERIALS AND METHODS}

Quantitative Analysis. Chili Guajillo puya (Capsicum annuum L.) was purchased in a local market in Morelos, Mexico. Samples were also provided by Laboratorios Bioquimex S.A. de C.V. (Mexico). This variety was chosen due to its high carotenoid content. After sun-drying, it was milled and sieved to obtain a flour with a particle size $\leq 1.4 \mathrm{~mm}$. Capsaicinoids were determined according to the method of Hoffman (1983) in an HPLC system equipped with a UV detector set at $280 \mathrm{~nm}$ and a $\mu$ Bondapack $C_{18}$ col umn $(3.9 \times$ $300 \mathrm{~mm})$. Acetonitrile/water, 1\% acetic acid, 40:60 (v/v), was used as eluent at a flow rate of $1.5 \mathrm{~mL} / \mathrm{min}$. Samples were purified in Sep-Pak cartridges according to the method of Attuquayefio and Buckle (1987). Carotenoids were measured in a Beckman spectrophotometer at $450 \mathrm{~nm}$, using $\mathrm{E}_{1 \mathrm{~cm}}^{1 \%}=$ 2500 for quantification after extraction either with ethanol or with ethanol/water mixtures. Under these assay conditions carotenoids are the main product detected (Mínguez-M osquera et al., 1981). Capsaicin of $90 \%$ purity from Sigma was used as standard. Proximate analysis of flour samples resulted in the following composition: humidity, 8.6; protein, 16.5; ashes, 6.5; fat, 8.1; crude fiber, 29.3; and carbohydrates, $31 \mathrm{~g}$ per $100 \mathrm{~g}$ of flour. Total capsaicinoids were 0.29 and total carotenoids $0.125 \mathrm{~g}$ per $100 \mathrm{~g}$ of flour and are included in the fat percentage.

Extraction Process. Several extraction options were analyzed in the course of this study. They are generalized in Figure 1. In general, three options were considered: water, industrial ethanol, and ethanol solutions. Water is a poor solvent for these products, but it is required for the enzymatic treatments prior to extraction.

Aqueous Enzymatic Treatment. Various enzymes were selected to soften the tissues in Capsicum peppers either before or during the extraction. All enzymes were from Novo N ordisk Industry: Olivex (an enzyme preparation from Aspergillus aculeatus mainly with pectolytic activity but containing also hemicellulolytic and cellulolytic side activities; $26000 \mathrm{pG} / \mathrm{mL}$ ), Celluclast (a preparation from Trichoderma reesei with celluIolytic activity; 1500 NCU/g), Viscozyme L (an enzyme preparation from Aspergillus with a wide variety of carbohydrase activities bearing $120 \mathrm{FBG} / \mathrm{mL}$ ), and Peczyme 5XAL (an enzyme preparation from Aspergillus niger with pectin esterase and arabanase activities, bearing 75000 AJ DU/mL and 90000 $\mathrm{UA} / \mathrm{mL}$, respectively). Enzymatic action was foll owed by measuring the release of reducing sugars with the DNS method (Miller, 1959). Treatment with enzyme in water was carried out with dried flour and $1-5 \% / \mathrm{mL} / 100 \mathrm{~g}$ of flour) of the enzymatic commercial product for $5 \mathrm{~h}$ at $50^{\circ} \mathrm{C}, \mathrm{pH} 4.5,120 \mathrm{rpm}$, and a 1:50 (w/v) flour/water ratio. The paste obtained was dried in a vacuum drier (Precision, Chicago, IL) at $50^{\circ} \mathrm{C}$ until water was reduced to $\sim 8 \%$ humidity. In all cases controls were performed in the absence of enzymes. All of the experiments were performed with three to five repetitions in batch process.

Ethanol Extraction. Extractions were carried out with industrial ethanol (96\% purity from ADYDSA, Mexico) both directly from dried flour and from the paste resulting after the aqueous enzymatic treatment. All of the experiments were performed by duplicates and in some cases by triplicates for 7 $\mathrm{h}$ at $50^{\circ} \mathrm{C}$ and a 1:50 (w/v) solid/solvent ratio, in a rotatory shaker (Gyratory Water Bath Shaker model G76) at 120 rpm.

Selective Extraction of Capsaicinoids and Colorants. To selectively extract capsaicinoids and carotenoids, the process was divided into two steps. In the first step, capsaicinoids were extracted from 1:50 (w/v) flour/solvent suspensions with 15 or $30 \%(\mathrm{v} / \mathrm{v})$ ethanol solutions at $50^{\circ} \mathrm{C}$, in a rotatory shaker at 120 rpm; after $7 \mathrm{~h}$, the mixture was filtered. The second batch extraction for the solids obtained was carried out under the same conditions but using industrial ethanol (96\%) as solvent to solubilize the largest portion of carotenoids.

Analysis with Light Microscopy. Sample Preparation. Dried chili flour was fixed for $3 \mathrm{~h}$, at $4{ }^{\circ} \mathrm{C}$, with a mixture of $2 \%$ formal dehyde and $2.5 \%$ glutaral dehyde in phosphate buffer (pH 7.0, $0.05 \mathrm{M}$ ); $2 \mathrm{mM} \mathrm{MgCl}$, was added to minimize the loss of lipids from the cells. Fixation was followed by washing with several batches of buffer, also for $3 \mathrm{~h}$. The flour was then dehydrated at $4{ }^{\circ} \mathrm{C}$ (each step lasting $\leq 1 \mathrm{~min}$ also to minimize lipid extraction) according to the following procedure: twice with $50 \%$ ethanol, a mixture of tert-butyl alcohol/ethanol/water 


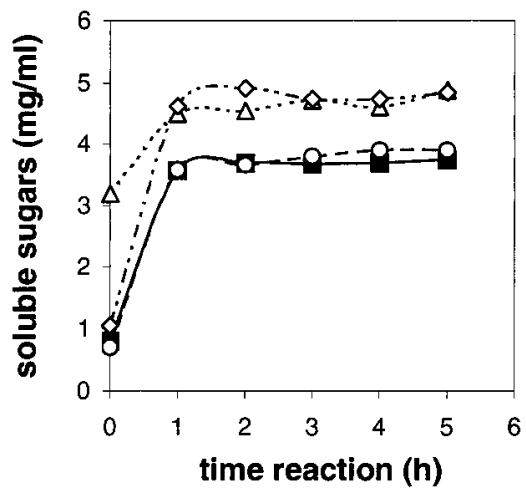

Figure 2. Production of soluble reducing sugars after aqueous enzymatic treatment of chili Guajillo puya flour: Viscozyme $L(\triangle)$, Olivex $(\diamond)$, Celluclast $(0)$, and control without enzyme (ם). Reaction conditions: $50^{\circ} \mathrm{C}, 5 \mathrm{~h}, \mathrm{pH} 4.5,120 \mathrm{rpm}$, flour to water relation of $1: 50$, and $5 \% \mathrm{v} / \mathrm{w}$ enzyme.

$(1: 4: 5,2: 5: 3,7: 10: 3,10: 9: 0)$, then with tert-butyl alcohol/ absolute ethanol (3:1), and finally twice with tert-butyl alcohol. The dehydrated flour was embedded in tert-butyl alcohol and paraffin (1:1), for $2 \mathrm{~h}$, at $60^{\circ} \mathrm{C}$ and then twice on paraffin at $60^{\circ} \mathrm{C}$, for $1 \mathrm{~h}$. Finally, it was included in paraffin, and sections of 4-6 $\mu \mathrm{m}$ were obtained with a microtome model J ung RM2035, from Leica.

Staining. Paraffin was removed from the sections by placing them in xylan (two steps, 2 min each) and then in a mixture of xylan and absolute ethanol (1:1), also for $2 \mathrm{~min}$. Afterward, sections were rehydrated in a graded ethanol series, starting from absolute ethanol to $50 \%$ ethanol, 1 min each step (ethanol concentrations decreased by $10 \%$ in each step).

Sections were examined with the following methods: Safranin and Picro Aniline Blue, periodic acid Shiff reagent (PAS) Amido Black (Clark, 1981), Coomassie Brilliant Blue R250 (Gahan, 1984), Sudan Black (Bancroft and Stevens 1996;

A

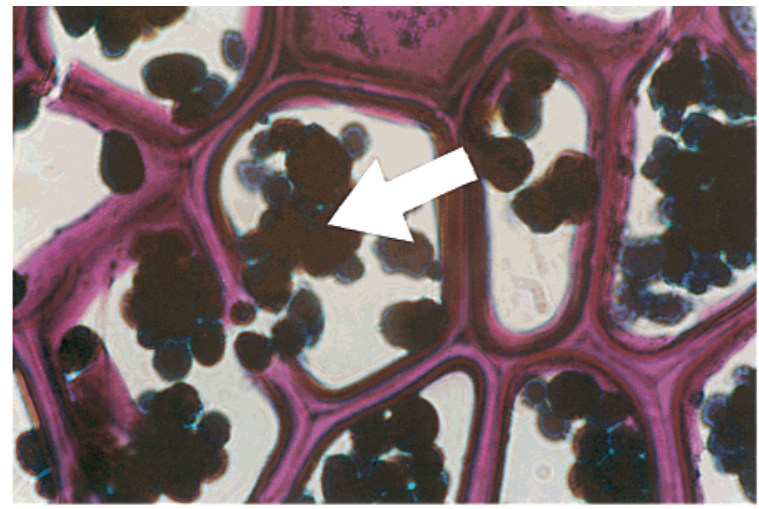

\section{C}

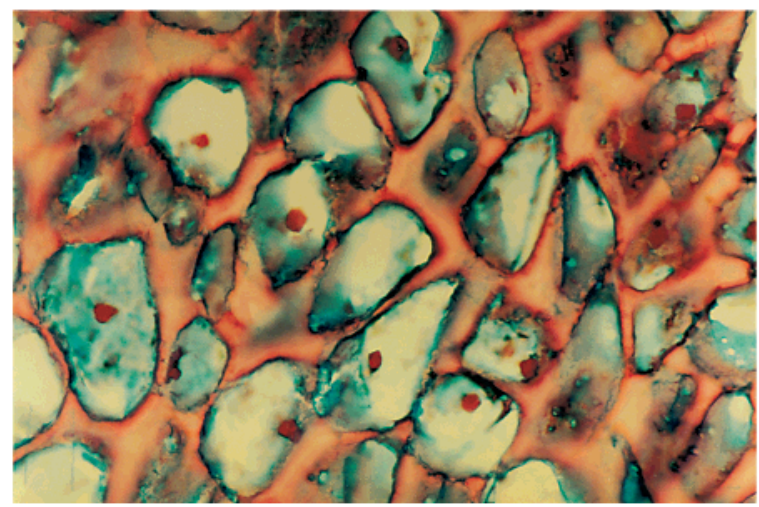

section were stained for $30 \mathrm{~min}$; the saturated staining solutions were also made in $70 \%$ propanol). For some of the stained sections, the original mounting media referred to in Clark (1981) was Canada balsam. In this work, Entellan was used to prevent col or fading. Pertinent results were the ones obtained with PAS-Amido Black and Sudan and, therefore, are the only ones presented.

\section{RESULTS AND DISCUSSION}

The feasibility of Capsicum extraction processes has been al ready demonstrated (Amaya Guerra et al., 1997). We found that $80 \%$ of capsaicinoids and $73 \%$ of carotenoids are extracted when industrial ethanol (96\%) is used as solvent under the experimental conditions described under Materials and Methods, values very similar to those already reported.

Capsaicin has a low solubility in water (Suzuki and I wai, 1984), so it is not surprising that during the treatment with water at $50{ }^{\circ} \mathrm{C}$ only $15 \%$ of capsaicinoids were found in solution. It has also been observed that some col orants, other than carotenoids, are extracted with water. Mínguez-Mosquera et al. (1992) reported that col oration in Capsicum aqueous extracts is due to a small amount of water-soluble col orants, presumably polyphenols, as the carotenoid fraction is soluble only in organic solvents.

Oil extraction by aqueous processes has been shown to be feasible when enzymes are used to break down vegetable tissue, allowing oil to be released from cells and collected after centrifugation (Buenrostro and López-Munguía, 1986; Cintra McGlone et al., 1986; Domínguez et al., 1994; Rosenthal et al., 1996). F or the case of chili flour, various enzymes were active toward some components during the enzymatic treatment, as
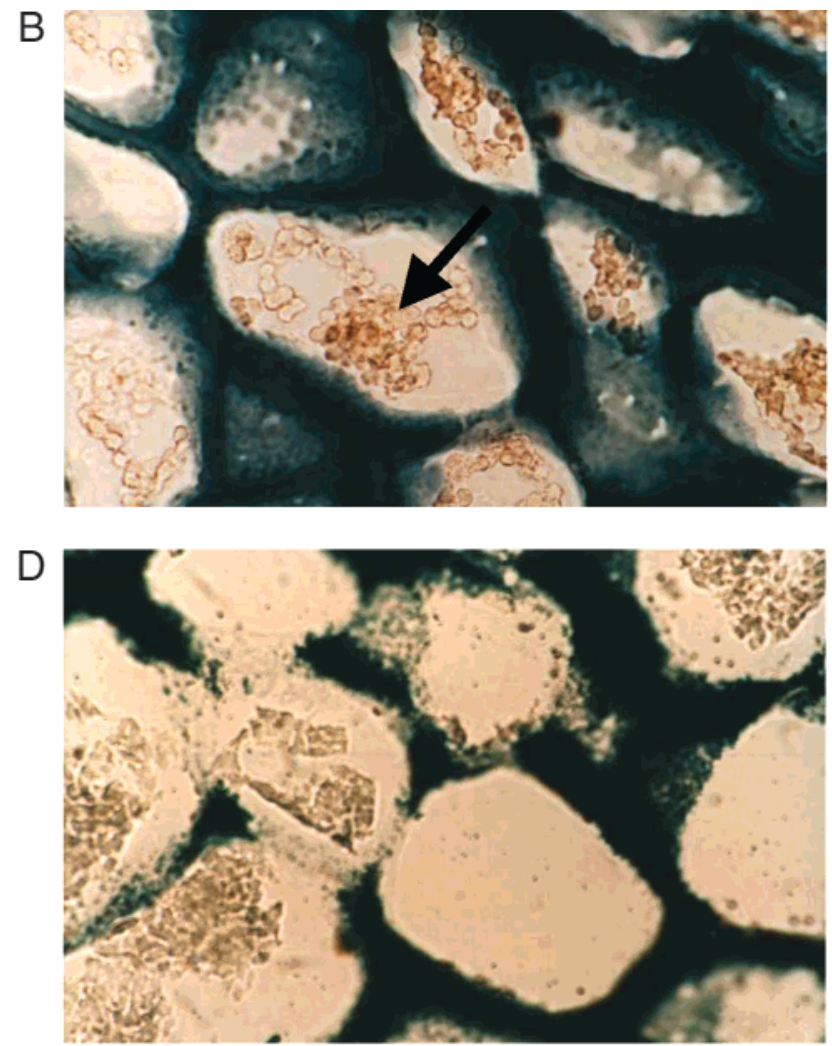

Figure 3. Light micrographs of chili flour (magnification $630 \times$; each panel is reproduced at $50 \%$ of its original size): (A) nontreated, stained with PAS-Amido Black (proteins stain blue, cellulose stains red); (B) nontreated, stained with Sudan Black (lipids, cutin, suberin, and waxes stain black); (C) nontreated, stained with Saphranin-Picro Aniline Blue (lignin stains red; cellulose stains blue); (D) pretreatment with Viscozyme L; (white arrow) protein bodies; (black arrows) lipid bodies. 
shown by a reduction in total mass and the increase in soluble reducing power during the first hour of reaction (Figure 2). However, an extraction yield of only $15 \pm$ $2 \%$ of capsaicinoids is obtained with or without the addition of different commercial enzymes such as Olivex, Viscozyme L, Peczyme $5 X A L$, or Celluclast at concentrations as high as $5 \%(\mathrm{v} / \mathrm{w})$ at $50^{\circ} \mathrm{C}$. Even when the temperature was increased to $80{ }^{\circ} \mathrm{C}$ after the enzymatic treatment, the yield remained low (17 $\pm 3 \%)$. These observations will be further discussed below.

The enzymatic treatments resulted in relatively low cell wall degradation (Figure 3); histological studies were carried out with the chili flour to analyze the cell wall structure/composition and the lipid distribution. Examination of the chili flour without treatment by light microscopy showed that the protein gl obules detected with Amido Black (Figure 3A) are also stained with Sudan Black (Figure 3B), a specific stain for lipids, cutin, and waxes. Taking into account that the oil content of Capsicum is $<8 \%$, it is possible that protein bodies consist of a matrix of proteins and lipids. Also, Zamski et al. (1987) reported that capsaicinoids are inside vesicles formed by the endoplasmatic reticulum that migrate to the cell periphery and are secreted to the cell walls into a subcuticular cavity. These observations might explain why the lignified cell walls (Figure 3C) are also stained with Sudan Black (Figure 3B). Lipids can be accumulated in the cell walls in the form of cutin.

On the other hand, we verified that with both enzymatic and water treatments, the shape and staining intensity of the lipid-protein matrix have changed when compared to untreated samples. In most cases, treated samples show a disform matrix, with less lipid content. Some of the cells are even depleted of intracellular content (Figure 3D). However, cutin is not removed from the cell walls, regardless of the type of treatment.

In the case of enzyme treatments, although in some cases a rapid increase in soluble reducing power was detected, as in the case of Viscozyme (F igure 2), we could not observe a significant rupture of the cell walls by optical microscopy because the material has been previously milled, and extensive cell wall rupture had al ready occurred. It is possible that the small increase in the oil extraction by enzymatic processes may be associated with the also small increase of the reducing power. Two main factors that hinder the increase in the yield of oil extraction by aqueous enzymatic processes may be involved: the small amount of oil in this type of seed (8\%), which hinders the extraction and recovery from aqueous environment; second, the complexity of the cell walls. Capsicum cell walls are cellulosic, but most of the cells are heavily lignified. This tissue also contains a great amount of cutin, which, in aqueous media, reduces the accessibility of enzymes to the cell wall material.

In the case of carotenoid extraction with industrial ethanol, an interesting result is obtained if the chili flour is dried after the aqueous enzymatic treatment. Figure 4 shows that while the same amount of carotenoids is extracted directly from the chili flour from samples presoaked in water followed by drying, when Viscozyme $\mathrm{L}$ or Peczyme 5XAL was added during the aqueous treatment, increases of up to $11 \%$ in carotenoids and $7 \%$ in capsaicinoi ds extraction yields were obtained. It is important to point out that yield is reported in terms of initial mass of chili used in the process, as an artificial

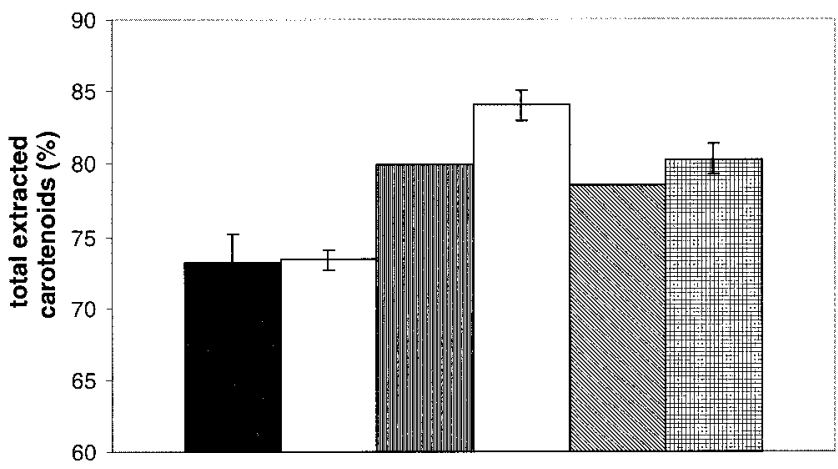

Figure 4. Ethanol extraction of carotenoids from chili guajillo puya flour directly from flour (black bar), after treatment with Viscozyme L 1\% (vertically striped bar) and 5\% (dotted bar) or Peczyme 5XAL 1\% (slashed bar) and 5\% (windowpane bar), and after treatment with water (white bar). Reaction conditions: $50{ }^{\circ} \mathrm{C}, 7 \mathrm{~h}$, agitation in a rotatory shaker at $120 \mathrm{rpm}$, solid to solvent relation of 1:50.
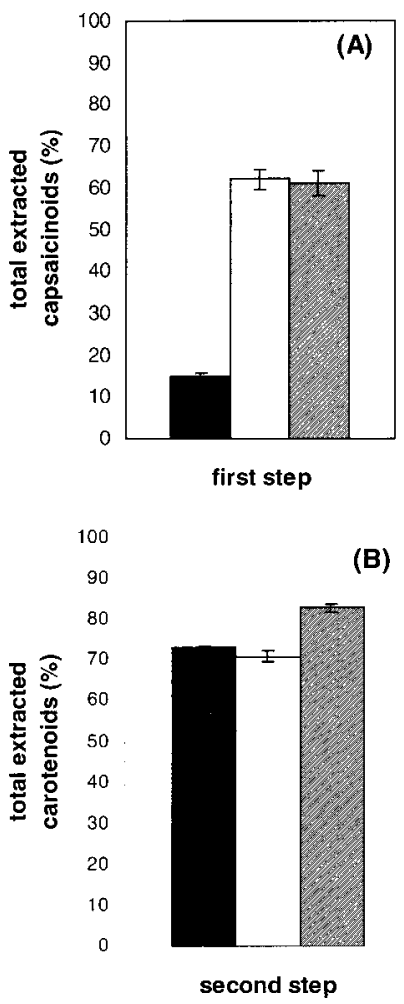

Figure 5. Two-step process for the selective extraction of capsaicinoids and carotenoids. In the first step, capsaicinoids are extracted with water (black bar), 30\% (v/v) ethanol (white bar), and $30 \% \mathrm{v} / \mathrm{v}$ ethanol after treatment with Viscozyme $5 \%$ (slashed bar). (A) In the second step carotenoids in all meals from the first step are extracted with $96 \%$ ethanol (B). Reaction conditions: $50^{\circ} \mathrm{C}, 7 \mathrm{~h}$, agitation at $120 \mathrm{rpm}$, and a solid to solvent relation of 1:50.

yield increase would result if the calculation were made from the final mass due to losses by solubilization.

To recover the maximum yield of capsaicinoids and carotenoids in separate fractions, we explored a selective extraction process. Although the separation of both compounds has al ready been reported by Amaya Guerra et al. (1997) and Balakrishnan and Verghese (1997), the proposed process requires the extraction of the ol eor esin. As shown in Figure 5, when water is substituted with up to $30 \%(\mathrm{v} / \mathrm{v})$ ethanol solutions, $62 \pm 0.1 \%$ of capsaicinoids may be extracted in the first step with a low removal of carotenoids (1.4\%). Afterward, in a second 
extraction with industrial ethanol, $70 \%$ of carotenoids and $26 \%$ of capsaicinoids are recovered. If an enzymatic pretreatment with Viscozyme $L$ is included in the process, then the final carotenoid extraction yield increases to $83 \pm 1 \%$. This is equivalent to an increase in the carotenoid extraction in the second step of $10 \pm$ $1 \%$.

These results demonstrate that ethanol is an interesting al ternative to hexane for the extraction of valuable products from Capsi cum, as it may be used directly for the extraction of $80 \%$ of capsaicinoids and $73 \%$ of carotenoids with a higher carotenoid extraction yield if the flour is previously treated with enzymes in an aqueous process. However, the best alternative is the selective extraction of both components in a three-step process: (I) pretreatment of the flour with an enzyme solution of Viscozyme L at 5\%; (II) a first extraction stage with $30 \% \mathrm{v} / \mathrm{v}$ ethanol to yield $60 \%$ of capsaicinoids (from both phases, water and 30\% ethanol); and (III) a second extraction stage with ethanol, during which most of the carotenoids (83\%) are obtained.

Despite the small increase in the extraction of carotenoids $(\sim 10 \%)$, a two-step treatment coupled with enzyme pretreatment may represent a significant economical alternative when its application to industrial processes is considered.

\section{ACKNOWLEDGMENT}

We are grateful to Novo I ndustry A/S for the enzymes and to Laboratorios Bioquimex for the supply of samples and information.

\section{LITERATURE CITED}

Abraham, G.; Hron, R. J., Sr.; Koltun, S. P. Modeling the solvent extraction of oilseeds. J. Am. Oil Chem. Soc. 1988, 65, 129-135.

Abraham, G.; Decossas, K. M.; Hron, R. J ., Sr.; Kuk, M. S. Process engineering economic evaluation of the ethanol extraction of cottonseed: preliminary analysis. J . Am. Oil Chem. Soc. 1991, 68, 418-421.

Abraham, G.; Hron, R. J ., Sr.; Kuk, M. S.; Wan, P. J . Water accumulation in the alcohol extraction of cottonseed. J . Am. Oil Chem. Soc. 1993, 70, 207-208.

Amaya Guerra, C. A.; Serna Saldívar, S. R. O.; Cárdenas, E.; Nevera Muñoz, A. Evaluation of different solvent systems for the extraction and fractionation of oleoresins from guajillo peppers. Arch. Latinoam. Nutr. 1997, 47, 127-130.

Attuquayefio, V. K.; Buckle, K. A. Rapid sample preparation method for HPLC analysis of capsaicinoids in capsicum fruits and oleoresins. J . Agric. Food Chem. 1987, 35, 777779.

Baker, E. C.; Sullivan, D. A. Development of a pilot-plant process for the extraction of soy flakes with aqueous isopropyl alcohol. J . Am. Oil Chem. Soc. 1983, 60, 12711277.

Balakrishnan, K. V.; Verghese, J . Studies on the recovery of pungency-free colour matter from I ndian capsicum extracts. Acta Alimentar. 1997, 26, 9-21.

Bancroft, J . D.; Stevens, A. Theory and Practice of Histological Techniques; Churchill Livingstone: New York, 1996; p 220.

Buenrostro, M.; López-Munguía, C. A. Enzymatic extraction of avocado oil. Biotechnol. Lett. 1986, 8, 505-506.
Busker, R. W.; van Helden, H. P. Toxicologic evaluation of pepper spray as a possible weapon for the Dutch police force: risk assessment and efficacy. Am. J . Forensic Med. Pathol. 1998, 19, 309-316.

Cintra MacGlone, O.; López-Munguía, C. A.; Vernon Carter, J . Coconut oil extraction by a new enzymatic process. J . Food Sci. 1986, 51, 695-697.

Clark, G. Staining Procedures, 4th ed.; Williams \& Wilkins: Baltimore, MD, 1981; pp 317, 323, 325-327.

Domínguez, H.; Núñez, M. J .; Lema, J . M. Oil extractability from enzymatically treated soybean and sunflower: range of operational variables. Food Chem. 1993, 46, 277-284.

Domínguez, H.; Núñez, M. J.; Lema, J. M. Enzymatic pre treatment to enhance oil extraction from fruits and oilseeds: a review. Food Chem. 1994, 49, 271-286.

Fullbrook, P. D. The use of enzymes in the processing of oilseeds. J . Am. Oil Chem. Soc. 1983, 60, 476-478.

Gahan, P. B. Plant Histochemistry and Cytochemistry, An Introduction, 1st ed.; Academic Press: London, U.K., 1984; pp 190, 204.

Hoffman, P. G.; Lego, M. C.; Gal etto W. G. Separation and quantification of red pepper major heat principles by reverse-phase high-pressure liquid chromatography. J . Agric. Food Chem. 1983, 31, 1326-1330.

Miller, G. L. Use of dinitrosalicylic acid reagent for determination of reducing sugar. Anal. Chem. 1959, 31, 426-428.

Mínguez-M osquera, M. I.; Fernández-Díez, M. J . Pimiento rojo Español maduro (genero Capsicum). Relación entre los pigmentos carotenoides rojos y amarillos. Grasas Aceites 1981, 32 (5), 293-298.

Mínguez-M osquera, M. I.; J arén-Galán, M.; Garrido-Fernández, J . Col or quality in paprika. J . Agric. Food Chem. 1992, 40, 2384-2388.

Napier, J . A.; Stobart, A. K.; Shewry, P. R. The structure and biogenesis of plant oil bodies: the role of the ER membrane and ol eosin class of proteins. Plant Mol. Biol . 1996, 31, 945956.

Rosenthal, A.; Pyle, D. L.; Niranjan, K. Aqueous and enzymatic processed for edible oil extraction. Enzymol. Microb. Technol. 1996, 19, 402-420.

Shabtai, Y.; Gotshal, N.; Ramot, O.; Wisniak, J . Enzymatic pretreatment of jojoba seeds to facilitate oil extraction. Indian J. Chem. Technol. 1998, 5, 124-130.

Shankar, D.; Agrawal, Y. C.; Sarkar, B. C.; Singh, B. P. N. Enzymatic hydrolysis in conjunction with conventional pretreatments to soybean for enhanced oil availability and recovery. J. Am. Oil Chem. Soc. 1997, 74, 1543-1547.

Sineiro, J .; Domínguez, H.; Núñez, M. J .; Lema, J . M. Ethanolic extraction of sunflower oil in a pulsing extractor. J . Am. Oil Chem. Soc. 1998, 75, 753-754.

Surh, Y.J .; Lee, R. C. J .; Park, K. K.; Mayne, S. T.; Liem, A.; Miller, J . A. Chemoprotective effects of capsaicin and diallyl sulfide against mutagenesis or tumorigenesis by vinyl carbamate and N-nitrosodimethylamine. Carcinogenesis 1995, 16, 2467-2471.

Suzuki, T.; I wai, K. Alkaloids; Academic Press: New York, 1984; Vol. 23, pp 227-299.

Zamski, E.; Shoham, O.; Palevitch, D.; Levy, A. Ultrastructure of capsaicinoid-secreting cells in pungent and nonpungent red pepper (Capsicum annuum L.) cultivars. Bot. Gaz. 1987, $148,1-6$.

Received for review November 17, 1999. Revised manuscript received April 14, 2000. Accepted April 17, 2000. This work has been supported by the E C funding I NCO-DC (OL NOCO), ERBIC 18CT970206.

J F 991242P 